\title{
ATTITUDES AND BEHAVIOR OF THE PUBLIC REGARDING CERVICAL CYTOLOGY: CURRENT FINDINGS AND NEW DIRECTIONS FOR RESEARCH*
}

\section{S. STEPHEN Kegeles}

Associate Professor of Public Health Administration, Department of Community Health Services, Public Health Practice Research Program, The University of Michigan School of Public Health, 122 South First Street, Ann Arbor, Michigan 48108

(Received 28 June 1967)

IN DISCUSSING problems concerned with inducing women to avail themselves of presymptomatic cervical cytology, focus will be on three topics:

(1) what is known or thought to be known about the attitudes and behaviour of the population regarding screening for cervical cancer;

(2) what problems there are in interpreting these data, and

(3) what kinds of research need be done in order to understand better the relationship between attitudes and health behavior generally, especially as this has relevance to cervical cytology.

I will exemplify this third point by discussing a research program currently in its planning stage with a first project on cervical cytology scheduled to go into the field within the next month.

Attitudes, beliefs, and behavior in regard to cancer in general, especially the voluminous material known under the general title of "delay" in visiting physicians with symptoms of cancer, has been analyzed quite completely in papers by KUTNER et al. [1], by GOLDSEN et al. [2], and by HENDERSON et al. [3] and need not be reviewed here.

\section{Current status of cervical testing in population}

First, a definition of the problem faced in presymptomatic cancer cytology. There are two ways of estimating the prevalence of cervical cancer testing in the population. The first is to make such estimates on the basis of the known number of tests given in private physicians' offices, clinics, or from cancer registries. A number of estimates of this kind have been made. For example, data from the Manchester project in

*Presented at the Seminar on Health Education in Uterine Cancer Programs, Ann Arbor, Michigan, 8 May, 1967.

This report was supported by the Public Health Service, Research Grant No. CH 00044 from the Division of Community Health Services. 
England [4] indicates the total number of smears taken during the years 1963-64, $1964-65$, by demographic status of women who have had tests. A study recently reported by HULKa [5] in Allegheny County, Pennsylvania, indicates these same relationships. Some of the data presented today indicate similar findings. Unfortunately, with this form of analysis it is difficult to determine the base population from whence the women derived who took cervical tests. Further, one is dependent for many of these analyses on physicians' reports which have been notoriously unreliable regarding morbidity data.

The second method of estimating the prevalence of cervical testing of the population is through interviews requesting information of women as to the frequency and recency of their having tests.

Three recent estimates have been provided from Alameda County [6] and San Diego City, [7] California, and from a study of a national probability sample of 1493 adults of whom 884 were women carried out by our research program. [8] The problem with these data is that they are dependent on the type of question asked, on whether women know that they have had tests, and on their recall. Even with their potential inaccuracies, the data from both kinds of estimates can be generally summarized in a few brief sentences. First, it appears that about $40-60$ per cent of the female population has had cervical cytology primarily during the last few years. Second, a relatively large number of women who have had single tests have failed to come back for repeat tests. Third, a number of women who may have had tests either were never told that they had cervical tests or failed to recall having them. Fourth, most cervical tests have been made in private physicians' offices generally as part of examinations for other purposes, and fifth, the populations who have failed to have cervical tests probably represent the highest risk groups, and tend to be those with relatively low income and education, who come from lower occupational groups, and are non-white. Rough as these figures are, there seems little question that there is sufficient problem with cervical cytology currently to necessitate program effort for a number of years.

One question posed by the conference is whether the data collected by social and behavioral scientists aid the health educator or health administrator to organize programs that will influence the many women who have not done so to avail themselves of cervical cytology. In an attempt to answer this question, the behavioral data are divided into three general groups:

(1) Data on attitudes or beliefs regarding cervical cancer,

(2) data which attempt to tie beliefs about cervical cancer to behavior, and

(3) data about other preventive health activities which may be relevant to women's taking cervical cytology.

After such presentation, some problems with these data will be noted by way of answering the question posed.

\section{Attitudinal data}

First, as to attitudinal data, the SOPHE Research Committee's Review of Research Related to Health Education Practice [9] indicated a number of studies in Russia by ORLOVSKY of female workers who refused to submit to cancer examinations. According to that secondary source (I have been unable to obtain the original data), 63 per cent of the women who refused were certain that their health was good, 10 per cent 
feared an operation in the event that cancer was found. It is also reported that Orlovsky found that one of the major factors in the failure to seek presymptomatic cancer examination was lack of knowledge about cancer. An English survey study [10] of some 1200 women indicated that half thought cancer was incurable, and that about 30 per cent thought that treatment made no difference. One variable which seems to have been found frequently in studies on "delay" is fear of cancer. An anecdote in regard to a study currently in the planning stage is worth mentioning here. Early plans were to have the study done using a health clinic within a poverty center as the focal place for cervical examination. It was reported to me by the director of the center that none of the community aides wanted the study done, though they were not to be involved in it, because they were completely afraid of having cancer mentioned within the poverty area. This necessitated a three-hour lecture emphasizing the fact that cervical cancer, if found in its early stages, is indeed curable.

DAvison [11] suggests, primarily as a result of anecdotal data from people who work in the field, that women may fear the test will inhibit one's sex life, that they may believe the test to be painful, that they may believe that only "dirty" people get cervical cancer. There are no data which indicate the extent of these latter beliefs in the population.

\section{Belief data related to behavioral data}

The most prominent of attempts to differentiate attitudes and beliefs of women who take cervical tests from those who fail to do so derive from the notions known variously in the literature as "The Hochbaum Model", "The Rosenstock Model", "The Behavioral Science Model", and most recently "The Health Belief Model". A brief description of the model seems necessary here, before discussing the data on cervical cytology. The model has suggested, based on a series of empirical investigations of tuberculosis screening, [12] penicillin prophylaxis for heart disease, [13] Asian influenza [14] and seeking preventive care for dental diseases $[15,16]$ that a person is unlikely to seek preventive care or health screening examinations unless he is ready to take such action. This state of readiness has been defined in the following way:

(1) a belief in susceptibility to the disease in question, and

(2) a belief that the disease in question would have serious effects upon one's life if contracted.

It has also been stated that some kind of "cue" needs to occur before the person in a state of readiness will take action. Such "cues" may come from outside the person in the form of publicity, or educational materials, or from within the person in the form of bodily symptoms.

Further, it has been stated, the person must be aware of certain actions that can be taken, and believe that these actions may reduce his likelihood of contracting the disease, or reduce the severity of the disease should he contract it. Finally, he must believe that the threat to him of taking the action is not as great as the threat of the disease itself.

Two separate studies have been performed explicitly using these variables for studying cervical cytology-one by FLACH [17] on women employed in the Division of Special Health Services of the Public Health Service in about 1960-and the national study mentioned earlier. [8] 
Certain problems occurred in the interpretation of data collected in both studies. For instance, the population in the Public Health Study was not a random sample of the population. Most of the women who worked in the particular public health unit studied had already taken cervical cancer examinations before they were studied. Thus the population had to be divided into an "up-to-date group" - those women who had taken at least one examination for uterine cancer within two years prior to the study and a "not up-to-date group"-those who either had not had examination in a 2-yr period prior to the interview, or who had never had cervical cytology. Almost all of the women in the study, perhaps because of their employment in the Public Health Service, recognized the value of early detection. Almost all of the women believed, as perhaps do most women in the population, that cervical cancer is a dread disease. Those women who were "up-to-date" differed significantly from those "not up-to-date" by their acceptance of the fact that they might get cervical cancer.

Within the national study, women were not asked specifically their beliefs about cervical cancer but were rather asked their beliefs regarding cancer in general. There are no data within the study which indicate women's feelings about their susceptibility to cervical cancer per se, or their beliefs about the seriousness of cervical cancer. Neither were they asked specifically their beliefs regarding methods for determining cervical cancer in its early stages. Data on the frequency of their Pap tests were gathered from general questions about special examinations which the women had for cancer. As indicated earlier, most of the women who had had cervical examinations stated that these examinations were done as part of another procedure while they were in a physician's office. Thus, it is not surprising that no relationship was found between the readiness factors, susceptibility to, and seriousness of cervical cancer, and whether women took cervical tests. It was found, however, that women who indicated a reliance upon professional diagnosis rather than self diagnosis of symptoms and who indicated the importance of early rather than delayed diagnosis were far more likely to have reported having cervical tests than their counterparts.

In fact, within every demographic analysis, women who believed in the benefits of early detection, and believed in the importance of professional judgment more often reported taking cervical tests than women without these beliefs. Almost twice as many white women with the beliefs reported taking tests as those without these beliefs, and twice as many non-white women with the beliefs took tests as those without beliefs. More married, single, and widowed and divorced women with the correct beliefs took tests than those without them. Within every age group, more women with the beliefs reported taking tests than did women without the beliefs. Within every income group, every educational group, and every occupational group, those with the beliefs reported taking more tests than those without the beliefs. Thus, one could predict correctly from demographic factors alone which groups of people would report taking tests. One could also make correct predictions from knowledge of their beliefs. However, the joint effects of beliefs and personal characteristics provided a much better assessment of reported tests than the effects of either alone.

One problem with these data should be fairly obvious. There is no way of knowing whether the women held such beliefs prior to getting cervical cancer cytology or whether women who had cervical smears taken gained such beliefs as a result of the procedure. Since we suspect that a number of women who might have had tests were 
unaware that tests were made, these data may indicate a correlation between the ability to report having had tests and the beliefs, rather than a relationship between having had the tests and the beliefs.

Data from other health activities relevant to women's taking cervical cytology

Of the whole body of data which indicate differences in sick-role behavior (as differentiated from presymptomatic behavior) as a reflection of group or cultural membership, the most interesting and creative seem-to me-to be those collected by ZoLA and colleagues $[18,19]$ and by SuCHMAN. [20, 21]

Zola started with the premise, supported by his survey of the literature, that most people have symptoms constantly and continuously which might be interpreted by health professionals as relevant to disease. This is contrary to the more general notion that people are ordinarily symptom-free, get symptoms at a specific time, and either act or fail to act on such symptoms. Zola suggests that the particular symptomsamong the totality experienced-which are acted on by any person are those defined by his particular culture, ethnic group, or reference group, as relevant for action. Such action occurs only after some "critical incident" occurs.

In an intriguing article, ZoLA [18] compared Italian and Irish patients who presented themselves at clinics at the Massachusetts General Hospital. He found for instance, that four times as many complaints from the Irish population concerned the eye, ear, nose, or throat than all other parts of their bodies combined, while only half of the complaints from the Italian population focused on the eye, ear, nose, and throat. Zola notes that only one third of the Irish patients indicated pain as part of their presenting symptoms while over half of the Italian patients indicated pain as part of their presenting symptoms. About 60 per cent of the Irish patients had problems of a specific nature as presenting symptoms while 70 per cent of the problems presented by the Italian group were quite diffuse. The studies by Suchman [21] concerning the various ethnic and cultural groups in New York City supplement the Zola data very well. Suchman notes that such conceptions as traditional family orientation, authority orientation, friendship cohesiveness and exclusivity, seem to vary greatly among ethnic groups in New York City, as these ethnic groups vary in the types of attitudes and beliefs about health which they hold and in the health practices they follow.

These are just a sample and not by any means all of the relevant data regarding social and attitudinal factors which seem to relate to people's seeking presymptomatic cancer examination.

\section{Relevance of data to health behavior}

A number of technical criticisms can be made of these data. These concern factors necessary to translate empirical concepts into scientific theory. Since the concern today is with thcir utility rather than their elegance, such criticism will be left aside. Instead, the focus will be on problems which make these data less useful than they might first appear.

First, as to attitude surveys as means of gathering information, people will generally answer questions posed them by interviewers in surveys. This will happen whether they have ever thought of the question before or not. Yet, there seems to be a growing body of data which indicate that such expressed attitudes have no functional significance unless they fit into the cognitive organization of the person. Thus Converse 
[22], in assessing the data from continued surveys of a panel of voters, has defined certain statements given by his respondents as "non-attitudes"- those which seem to have no relationship to their voting or to anything else. Given the fact that most attitude surveys are performed on a one-time basis, we don't know whether the beliefs which underlie such expressions persist, or are only present at the particular time the respondent is interviewed. Perhaps even more important is the fact that most behavior occurs as the result of a multitude of factors which interact together in a particular space-time sequence. Without demonstration that such attitudes have relevance for behavior, they provide merely interesting and perhaps useful hypotheses for further test.

It was partially to avoid the pitfalls of the simple attitude survey that the format of studies within the context of the Health Belief Model were performed. That format attempted to relate belief and attitudinal data to verbal statements of health behavior by the population studied. Analyses were done differentiating the population into those who took preventive action and those who failed to do so.

Unfortunately, some problems of the attitude survey were not thereby avoided. Most of the data which led to the model were collected through single surveys in which both belief and behavioral data were gathered in the same interview. In all but two cases, the behavior in question had been performed prior to the interview. Survey research strategy of this kind can lead to conclusions about relationships but not conclusions about causality. Though the investigators were careful in presenting the data as relational, it has been easy to read into the material the conception that, for instance, a belief that one is susceptible to a disease leads him to take certain actions. It is just as easy to interpret these data as indicating that a person will change his beliefs as a result of having taken an action, in order to rationalize the action taken. If the latter were true, there would be no particular differences in people's attitudes and beliefs before the health action, but great differences after the action. The Zola data mentioned earlier-collected from people who presented themselves at a clinic after they were ill and the many other studies which attempt to understand reasons for coming from people who arrive for medical attention - suffer from the same defects.

The two studies from the Health Belief group in which the behavior took place long after the belief data were collected should have solved this problem. In both cases, certain problems occurred. In the first study-that of Asian influenza [14]-the spread of the epidemic moved much faster than had been anticipated. The sample on which the test of the model could be made was reduced to 86 persons. Only 12 of the 86 persons scored relatively high in regard to their readiness to take action. Five of these 12 subsequently made preventive preparation relative to influenza. Of the total of 74 persons who were defined as unmotivated, only eight subsequently made preparations. Although there was a substantial and significant difference between the two groups, the reduced sample size raises questions.

The second prospective study was a follow-up of the dental behavior of a population studied previously. Three years after the initial collection of beliefs and dental behavioral data, a mail questionnaire was sent to each person in the sample as well as to a comparable control group to obtain information about their three most recent dental visits. The objective of the follow-up was to determine whether the beliefs identified during the original study were associated with behavior during the subsequent 3-yr period. [16] In that follow-up study, perceptions of seriousness were 
not associated with preventive behavior; perceptions of benefits taken alone were not related to preventive behavior; however, there was a strong relationship between taking preventive dental visits and the joint factors of susceptibility and benefits. However, the best prediction of subsequent behavior was previous behavior. Thus people who stated they took preventive visits when interviewed the first time continued, for the most part, to make preventive dental visits; almost every person who stated he had made symptomatic visits when interviewed originally made subsequent visits for symptomatic purposes. Thus beliefs, even in that prospective study, might have been rationalizations to explain why the person continued his habitual behavior rather than a prior condition to action.

The second problem with much of these data is that we have no real idea as to what constitutes a sufficient "cue" to set off the state of readiness in the Health Belief Model-or the "critical incident" which brings a person to accept certain symptoms as relevant enough to see a physician in the Zola conception.

For instance, in the national study there was found to be no relationship between perceptions of seriousness or of susceptibility, and taking preventive health actions in regard to dental diseases, tuberculosis, or cancer in general. This failure to duplicate findings from earlier specific studies has been explained by those of us involved as due to an absence of "cue" factors to trigger the state of readiness of the population to act in these three areas. Unlike the specific populations studied previously, all of whom had been in situations where external stimuli were present (e.g., campaigns in the three cities in which the tuberculosis data were collected, publicity about the spread of Asian influenza at the time of the Asian influenza study, membership in a prepaid company dental program for the dental studies), the national sample population had no particular external influences which stimulated them to act.

To review the points made, concern has been voiced with the various data for the following reasons: (1) in studies concerned with attitudes alone such attitudes may have no counterpart in behaviour, (2) in studies in which verbal statements of retrospective behavior were collected at the same time as belief and attitudinal data, it is just as reasonable to conclude that behavior causes belief as that belief causes behavior, (3) there are few indications of the types of "cues" necessary to produce health behavior, and (4) there are few indications of the persistence or reality of the attitudes and beliefs studied. However, it is not advocated that these data and notions be discarded. Rather, what is suggested is that these studies be treated as they were originally intended-as hypothesis generating studies rather than as hypothesis testing studies. In answer to the question raised initially, I don't believe the data available now give adequate foundation for health education programs. However, they do provide starting points for other studies.

\section{Types of studies to be done}

To be explicit, one kind of needed study would have five characteristics. First, the beliefs and previous behavior of a population should be determined prior to its being offered a health service. Second, one should intervene through some known mode or modes of communication in an attempt to change these attitudes and beliefs. Third, one should measure the attitudes and beliefs subsequent to the communication; fourth, one should measure the changes in behavior which occur as a result of the communication; and, of course, fifth, the necessary controls should be built into the 
study to insure that any changes which occur do so as a result of the treatment and not through uncontrolled circumstances. This kind of study will be illustrated through research activity to be outlined later.

The types of studies described resemble the communication and persuasion studies performed by social psychologists during the last $15 \mathrm{yr}$. Since the seminar program lists a subsequent presentation of these studies, time to discuss such studies need not be taken here. However, it should be indicated that many studies have demonstrated that an experimenter, through the use of oral or written communications, can change the attitudes of experimental subjects. However, most communication-persuasion studies have used subjects drawn from college populations. Studies on cognitive dissonance have used artificial and contrived situations which seem to have little apparent relevance to the real world. Almost no studies have indicated the effectiveness of standard communications on changing attitudes, which, in turn, lead to changes in behavior in any context.

\section{Populations to be studied}

Though almost any population is legitimate for study, it seems relevant to place emphasis on populations who have failed to take health actions. Thus, the RADELFINGER study [23] which gathered pre-attitudinal data, used a known communication, and collected behavioral data was done with college students, who for the behavior in question were not "real" people. As a result, analysis was almost impossible since nearly all of the subjects failed to get tetanus shots.

On the other hand, some studies done by Leventhal $[24,25]$ on tuberculin screening and smoking at a health exhibit, and urging college students to make visits to a University Health Clinic used populations who were relevant for the behavior in question.

Studies in the planning stage by KIRSCHT concerned with influencing state employees to use seat belts uses a relevant population. The junior high school students used by HAEFNFr [26] in his study of the effects of different types of communications on changing dental behavior was a relevant population for that study.

For studies of cervical cytology, the population that lives in Negro ghetto areas within urban centers seems very relevant. That same population seems very relevant for many studies on health behavior. For, despite a few instances in which Negroes more often than whites took advantage of available health services (BELCHER [27] in regard to Salk vaccine, Elinson et al., [28] in regard to chronic disease screening, KEGELES et al. [29] in regard to acceptance of dental care) Negroes tend to use health services, make screening visits, and accept immunization less frequently than do whites.

\section{The type of communication to be used}

Research needs to be done on what people are told or not told, on how they are communicated to (e.g., in ways intended to increase their feelings of threat as in the Hatrner [26] or Leventhal [24, 25] sludies), by whom (hey are communicated to (e.g., by people like themselves, or by people seen as experts in health), and by different media. There are almost no data which help define how and what a message should be in order to persuade specific populations to take health actions.

For the population with which the author is concerned, the urban Negro popula- 
tion, early studies of audience response to mass communications indicated that they were not well attended by persons in the lower income and lower educational groups (Schramm, [30] Davis. [31]) Recent data presented by SwineharT [32] indicate that radio and television exposure was greater among Negro than white populations. That finding offers some interesting possibilities for health educational activities. In my particular case, I was interested in a selected population which made mass efforts difficult to control.

In certain health programs, efforts have been made to use indigenous leaders for communicating the facts about the availability of health care. Yet, there is some evidence that lower class Negroes neither belong to organizations, nor refer on most matters to other than relatives and neighbours (COHEN and HoDGES, [33] CORNELY and Bigman, [34] Miller and Reisman. [35]) This appears to be true in regard to health matters as well (Cornely and Bigman, [34] Cowles and Polgar. [36]) Moreover, problems of situational convenience seem highly relevant to persons in lower "class" populations who may tend to be homebound because of difficulties in obtaining transportation and because of the presence of younger children. In the three studies in which Negroes responded more favorably than whites, health care and health screening was made available at no cost, with maximum convenience including free transportation, and with personal solicitation or induction to come in for care or screening. Thus, it seemed most sensible to use a format of personal, house to house appeals for every subject, and most appropriate to use a format of "packaging" research [37] for experiments with this population; that is to use every possible mechanism to bring the population in question into clinics or office for screening or preventive examinations. I intend to use groups who are as close as possible to clinics where examinations are to be given and to keep clinics open at hours which are most convenient to the populations in question, to make the source of messages credible by using both a "trustworthy" source (a "community aide"), and an "expert" source on a personal basis, and to use group pressures whenever possible for both experimental and control groups.

The variables which make up the Health Belief Model, continue to be a personal interest. However, there is desire to find out:

(1) whether people with appropriate beliefs will actually take a particular action,

(2) whether these beliefs can be changed by a communication intended to doso, and

(3) whether such changes in beliefs do in fact lead to changes in behavior.

TABLE 1

\begin{tabular}{|c|c|c|c|c|c|}
\hline & $\begin{array}{c}\text { Pre- } \\
\text { Interview }\end{array}$ & $\begin{array}{l}\text { S.B. Com- } \\
\text { munication on } \\
\text { cervical cancer }\end{array}$ & $\begin{array}{l}\text { Communication } \\
\text { on iron } \\
\text { deficiency }\end{array}$ & $\begin{array}{l}\text { Communication } \\
\text { on where } \\
\text { and when }\end{array}$ & $\begin{array}{c}\text { Post } \\
\text { interview }\end{array}$ \\
\hline $\mathbf{A}_{1}[35], \mathbf{B}_{1}[35]$ & V & $\checkmark$ & & $\checkmark$ & $\checkmark$ \\
\hline$A_{2}[35], B_{2}[35]$ & $\checkmark$ & & $\checkmark$ & $\checkmark$ & $\checkmark$ \\
\hline C [35] & & $\checkmark$ & & $\checkmark$ & $\checkmark$ \\
\hline D [35] & & & $\checkmark$ & $\checkmark$ & $\checkmark$ \\
\hline$E[20]$ & $\checkmark$ & & & & $\checkmark$ \\
\hline
\end{tabular}


Table 1 is an attempt to indicate the design of the study in simplified form. Only the broad outlines of the study are indicated. Three separate blocks have been chosen to represent the experimental cells in the field experiment. They contain approximately 70 households each, chosen on the basis of similarity in demographic factors (amount of education, income, and type of employment of head of household) and in distance from the health center. The three blocks will be split up into two halves giving six separate experimental cells. One adult female (25-55 yr of age) in each household of four of the six cells $\left(A_{1}, B_{1}, A_{2}\right.$ and $B_{2}$ ) (or two of the three blocks) will be interviewed in regard to:

(a) her beliefs about the likelihood of getting cervical cancer, and her perception of the available means for preventing and/or screening for this disease;

(b) her previous behavior in regard to cervical cancer; and

(c) whether she intends to visit the clinic for screening.

Other data will also be gathered.

Approximately one week after the original interview, a "communicator"-an indigenous person who has been trained for a short period of time will visit each household in each of the three blocks. In three of the cells $\left(A_{1}, B_{1}\right.$, and $\left.C\right)$, the communicator will read material from a simple booklet which emphasizes the extent to which these women are susceptible to cervical cancer, and the potential benefits from early detection of cervical cytology.

In the remaining three cells $\left(\Lambda_{2}, B_{2}\right.$, and $\left.D\right)$, the communicator will read a communication concerned with iron deficiency comparable in emphasis, length, and in number of pictures. In all six cells, the communicator will indicate where, what, how, and when cervical tests will be given. A written communication giving the location of the clinic and the hours in which it will be open will be left at each household.

One week subsequent to the communication, a physician will be placed in the clinic to which the sample has been urged to come for cervical cytology. Each woman who comes to the clinic will be interviewed in regard to:

(a) her beliefs about her perceived susceptibility to cervical cancer, and her perception of the efficacy of screening tests for cervical cancer;

(b) the referral system which she used (if any) which brought her to the clinic;

(c) the barriers which she had to overcome in order to visit the clinic.

Each woman who failed to come to the clinic for screening will be interviewed at her home in order to assess:

(a) her perceived susceptibility to cervical cancer, and her perception of the efficacy of screening tests for cervical cancer;

(b) the referral system which she used (if any) to avoid coming to the clinic; and

(c) the factors which she saw as barriers to visiting the clinic.

We expect, from the study, to begin to get some indication of:

(1) the rclationship between certain pre-attitudes and behavior,

(2) the relationship between communications intended to change attitudes and behavior,

(3) the interaction between pre-attitudes and communications intended to change these pre-attitudes,

(4) the impact of home visits generally on changing behavior, and

(5) some notion of why certain people fail to behave following certain communications. 
Obviously, however, a single study of this kind will give only some slight indication of the effect of a particular communication in regard to one specific behavior, that of cervical cytology. Even if the study is successful, it needs to be repeated for other preventive or screening activities.

It should be obvious from this presentation that the first study in the program deals only with getting women to come in a single time for cervical cytology. Research needs to be done manipulating the types of information given to women to determine relevant communications for inducing repeat visits for cervical cytology. Lee Holder, a doctoral student, is interested in examining the question of which person is likely to be most effective in communicating information. He intends to determine whether Negro communicators who can be identified as being like the population in question are more likely to change attitudes and behavior of a population than are middle-class Negroes or middle-class whites.

It should be made explicit here that the particular format presented is merely one of a number of types of research which can be done. Many other field experimental studies can be done by health educators within their own program areas. Thus, the study reported a few years ago by RoBerts, Mico and Clark [38] which used two different approaches to communicate to an Indian population was quite simple yet produced extremely interesting findings. Unfortunately, as far as is known that study was not followed up by studies of a similar nature.

Now to summarize these various thoughts. First, there was noted the current status of cervical cytology in the country. Second, the question was asked, "Do the current data from social and behavioral studies help very much in planning programs in the health area?" A review and critique of some of these data seem to indicate that they should be seen as starting hypotheses for studies which experimentally manipulate these variables. Some general statements were made as to the kinds of studies which seem to be needed exemplified by a particular program of research with which the author is currently involved. Only after variables of these kinds are seen "to work" can there be much confidence in their real applicability in programs.

\section{REFERENCES}

1. Kutner, B., Makover, H. B. and Oppenheim, A.: Delay in the diagnosis and treatment of cancer: a critical analysis of the literature, J. chron. Dis. 7, 95-120, 1958.

2. Goldsen, R. K., Gerhardt, P. R. and Handy, V. H.: Some factors related to patient delay in seeking diagnosis for cancer symptoms, Cancer 10, 1-7, 1957.

3. Henderson, J. G., WitTKower, E. D. and Lougheed, M. N.: A psychiatric investigation of the delay factor in patient to doctor presentation in cancer, J. psychosom. Res. 3, 27-43, 1958.

4. WAkefield, J. and Baric, L.: Public and professional attitudes to a screening program for the prevention of cancer of the uterine cervix, a preliminary study, Br.J. prev. soc. Med. 19, 151-158, 1965.

5. HulKa, B. S.: Motivation techniques in a cancer detection program, Submitted for publication to Publ. Hlth Reps.

6. Breslow, L. and Hochstim, J. R.: Sociocultural aspects of cervical cytology in Alameda County, Calif., Publ. Hlth Reps. 79, 107-112, 1964.

7. American Cancer Society, San Diego County Branch: Papanicolaou Smear Survey, City of San Diego, San Diego, Calif., June, 1961.

8. Kegeles, S. S.. Kirscht, J. P., HAefner, D. P. and Rosenstock, I. M.: Survey of beliefs about cancer detection and taking papanicolaou tests, Publ. Hlth Reps. 80, 815-823, 1965.

9. Society of Public Health Educators Research Committee, Review of Research Related to Health Education Practice, Health Education Monographs, p. 70, Supplement No. 1, 1963. 
10. Paterson, R. and Aitkea-Swan, Jr.: Public opinion on cancer-A survey among women in the Manchester area, Lancet 11, 857-861, 1954.

11. Davison, R. L.: Carvical cytology: A challenge to health education, Int. J. hlth Educ. 9, 178-182. 1964.

12. Hоснвачм, G. M.: Public participation in medical screening programs: a sociopsychological study, Public Health Service, Public Health Service Publication No. 572, Washington, United States Government Printing Office, 1958.

13. HeinzelmanN, F.: Determinants of prophylaxis behavior with respect to rheunatic fever, J. Hlth hum. Behav. 3, 73-81, 1962.

14. Leventhal, H., Rosenstock, I. M., Hochbaum, G. M.: Epidemic impact on the general population in two cities, in The Impact of Asian Influenza on Community Life: A Study in Five Cities, United States Department of Health, Education, and Welfare, Public Health Service, Publication No. 766, 1960.

15. Kegeles, S. S.: Some motives for seeking preventive dental care, J. Am. dent. Ass, 67, 90-98, 1963.

16. KeGELes, S. S.: Why people seek dental care: A test of a conceptual formulation, J. Hlth hum. Behav. 4, 166-173, 1963.

17. FLACH, E. G.: Participation in a casefinding program for cervical cancer, Administrative Report, Cancer Control Program, United States Public Service, Washington, D.C., 1960.

18. ZoLA, I. K.: Culture and symptoms-an analysis of patients' presenting complaints, Am. sociol. Rev. 31, 615-630, 1966.

19. Stoeckle, J. D. and Zola, I. K.: Views, problems, and potentialities of the clinic, Medicine 43, 413-422, 1964.

20. Suchman, E. A.: Socio-medical variations among ethnic groups, Am. J. Sociol. 70, 319-331, 1964.

21. Suchman, E. A.: Social patterns of illness and medical care, J. Hlth hum. Behav. 6, 2-16, 1965.

22. Converse, P.: Attitudes and non-attitudes: continuation of a dialogue, Paper presented at the 17th International Congress of Psychology, Washington, D.C., 1963.

23. RADELFINGER, S.: Some effects of fear-arousing communications on preventive health behavior, Hlth Educ. Monographs 19, 2-15, 1965.

24. Leventhal, H. and Kafes, P. N.: The effectiveness of fear arousing movies in motivating preventive health measures, $N . Y$. St. J. Med. 63, 867-874, 1963.

25. Leventhal, H., Singer, R. and Jones, S.: Effects of fear and specificity of recommendation upon attitudes and behavior, J. Personal. soc. Psychol. 2, 20-29, 1965.

26. HaefNer, D. P.: Arousing fear in dental health education, J. Publ. Hlth Dentistry 25, 140-146, 1965.

27. Belcher, J. C.: Acceptance of the Salk polio vaccine, Rur. Sociol. 23, 158-170, 1958.

28. Elinson, J. and Trussell, R. E.: Chronic illness in a rural area, In Chronic Illness in the United States, Cambridge, Mass., Harvard University Press, Vol. 3, p. 440, 1959.

29. Kegeles, S. S., LotzKar, S. and Andrews, L. W.: Predicting the acceptance of dental care by residents of nursing homes, J. Publ. Hlth Dentistry 26, 290-302, 1966.

30. Schramm, W.: Mass communication, A. Rev. Psychol. 13, 251-283, 1962.

31. Davis, R. C.: The public impact of science in the mass media, Ann Arbor: Survey Research Center, 1958.

32. SwINeHART, J. W.: Voluntary exposure to health communications, accepted for publication in Am. J. Publ. Hlth.

33. CoHeN, A. K. and Hodges, II. M.: Characteristics of the lower-blue-collar class, Social Problems 10, 303-334, 1963.

34. Cornely, P. B. and Bigman, S. K.: Cultural considerations in changing health attitudes, D. C. Med. Ann. 30, 191-9, 1961.

35. Miller, S. M. and ReISman, F.: The working class subculture: a new view, Social Problems 9, 86-97, 1961.

36. Cowles, W. and Polgar, S.: Health and communication in a Negro census tract, Sucial Prablems 10, 228-36, 1963.

37. JAMES, G.: Program planning and evaluation in a modern city health department, Am. J. Publ. Hlth 51, 1828-1840, 1961.

38. Roberts, B. J., Mico, P. R. and Clark, E. W.: An experimental study of two approaches to communication, Am. J. Publ. Hlth 53, 1361-1381, 1963. 